\title{
Improving Independence of Elderly People by Introducing Smart Products: The Guide Me Localization Case
}

\author{
J. P. Joore
}

Received: 15 December 2006 / Accepted: 15 March 2007 / Published online: 13 July 2007

(C) Springer Science + Business Media B.V. 2007

\begin{abstract}
What are the potential benefits of introducing technological innovations when working on issues with a wider societal impact? Focusing on a specific care and housing corporation for elderly people, the Sustainable System Innovation process has been used to translate an innovation challenge on macro societal level: "How can we deal with the challenges that occur due to the aging of society?" to a concrete innovation challenge on microtechnological and user level: "How can a tracking device be designed for optimal use by elderly person and care giver?"
\end{abstract}

Keywords Sustainable System Innovation · Customized products . Alzheimer localization device . Guide $\mathrm{Me}$

\section{Introduction}

How can the long-term goals of society be connected with short-term innovation goals of commercial organizations? How can the societal challenge of the

\section{J. P. Joore $(\square)$}

TNO Science \& Industry,

Eindhoven, The Netherlands

e-mail: peter.joore@tno.nl

\section{J. P. Joore}

Design for Sustainability Group, Faculty of Industrial

Design, Delft University of Technology,

Delft, The Netherlands aging population ${ }^{1}$ be translated in promising business innovations? This paper describes an innovation project where the long-term challenges regarding the growing amount of elderly people in the Netherlands is being translated in a specific short-term solution for a Dutch Society of Manufacturing Engineers (SME) company. Although this issue is high on the political agenda, it is clear that this issue should not only be left to the government to solve nor to commercial organizations alone. Instead, it should be handled as an innovation challenge for companies, care organizations, researchers, and government together, combining the more broad perspective of policy makers with the more detailed technological innovative capabilities of designers and commercial companies, creating appropriate answers to this important challenge for society.

This paper describes a project in which the Sustainable System Innovation (SSI) approach is used to support this process by connecting a rather topdown macro perspective with a more bottom-up technological perspective. During the project, a close cooperation with a Dutch care and housing organization "De Woonmensen" in Apeldoorn has been developed. This organization is currently in the process of drastically renovating one of their living areas called Hubertus. The main focus of the new

\footnotetext{
${ }^{1}$ The expected amount of people above 65 years old will be 3.2 billion in 2020 , one billion more than in 2003 , forming $18.6 \%$ of the total population, in contrast with $13.5 \%$ in 2003 (Centraal Bureau voor de Statistiek 2005).
} 
neighborhood will be the fact that all people will be living independently, instead of the current more institutionalized elderly home. For the Woonmensen, an important area of attention regarded the possible benefits of technological innovations to support this vision of all people living independently.

In the process of the project, a specific innovation has been selected for further development. This concept, called the Guide Me system, enables care personnel to track the position of people so they can always be found in case of emergency. The commercialization of this concept is being done by a Dutch SME company, My Bodyguard BV in Haaksbergen. Within the same overall research, other researchers have focused on among others the realization of ecological improvements like energy reduction in the new neighborhood. This is not described in this paper. The paper is adapted from another study (Joore et al. 2005).

\section{The System Innovation Vision}

In the project, a specific innovation approach has been followed to translate a societal need on macro level into the creation of a so-called strategic niche experiment involving a specific technological innovation. The approach focuses on the total system at hand and tries to create synergetic advantages between several actors and combine needs that are usually only handled separately. The expectation is that smart combinations of needs and functions can improve the ecological and social footprint of the integrated solution being developed. ${ }^{2}$ The background of the approach taken is the method for SSI (Weterings 2002; Fig. 1), involving the following steps:

Step 1: Development of future scenarios, based on extrapolations of the present situation, describing what would happen without interference of the organizations involved in the innovation process

Step 2: Development of sustainable future visions, describing an "ideal" situation, looking ahead 10-15 years, not being limited by present day limitations

\footnotetext{
${ }^{2}$ For example, a person performing a certain care task could possibly combine this with other tasks, now done by other organizations, reducing the amount of care personnel needed to be involved with a certain client.
}

Step 3 and 4: Backcasting from the envisioned situation to the present situation. Creating a roadmap showing the various steps that are needed to get from the present situation toward the envisioned situation and clarifying the position of the niche experiment as one of those steps

Step 5: Creation and execution of a strategic niche experiment (Kemp and Rotmans 2001), to be executed within 1-3 years, as a strategic step in the long-term innovation process.

In each of the steps taken, the various actors play a unique role in the decision-making process. As the innovation process needs to take place on different abstraction levels, this can be considered as a "Vcycle for system innovations" (Joore 2006). During the project, the translation takes place from the top level problem definition, going down step-by-step until a specific bottom level technological issue is selected.

While evaluating the solutions, the analysis should be done on the same abstraction level as the problem definition was defined, going up step-by-step analyzing the impact of a certain aspect on the selected issue that lies one level higher. This process is visualized in Fig. 2, where the top level represents a societal relevant issue on a relatively high abstraction level. Going down step-by-step, the problem description gets to a more and more concrete level, where the lowest level represents a rather narrow technological innovation track. In the following chapter, only those steps of the total research process that specifically relate to the development of the Guide Me system have been described.

\section{Future Scenario Development}

The macro level problem definition of the project determines the driving mission behind the whole innovation process, to which the results of the project should contribute. In this project, the expected rising pressure on society as a result of the growing percentage of elderly people is selected as the main subject of attention. The hypothesis was that technological innovation can assist in reducing these costs, 
Fig. 1 Sustainable system innovation scenario, from (Weterings 2002)

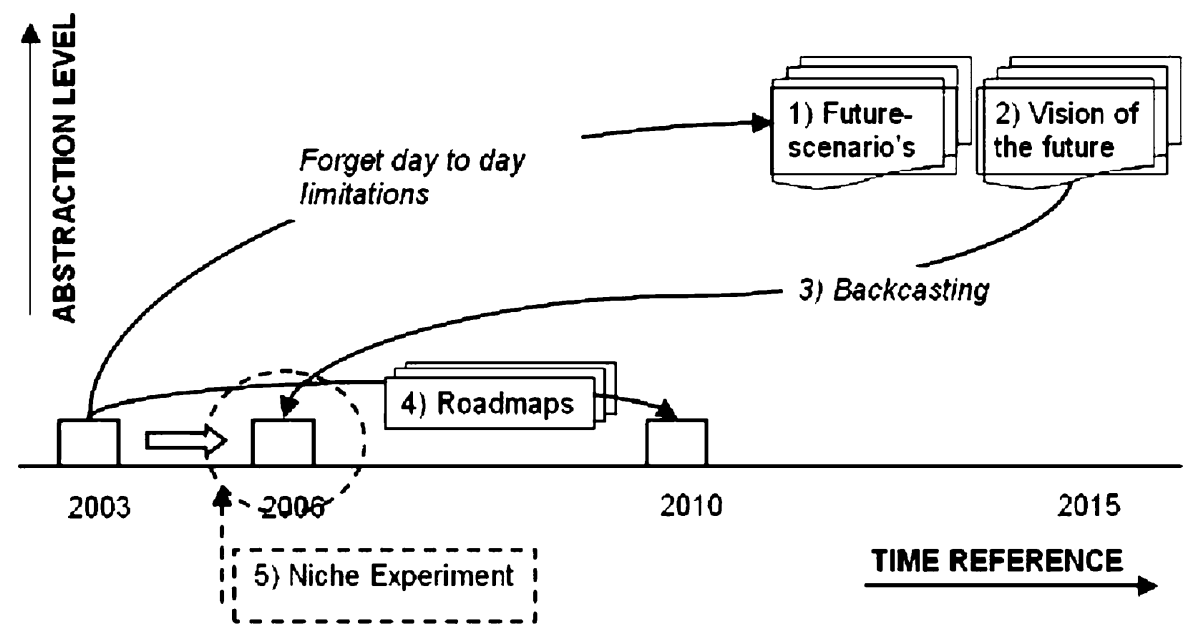

if applied in the right way. The purpose of the innovation process has been described in the following challenge: "How can we deal with the challenges that occur due to the aging of society?"

Involvement of Relevant Actors in the Process Where normal innovation processes often start from the commercial perspective of one specific company, one of the main issues in the SSI approach is to involve other actors in the innovation process from the start on. This ensures that relevant societal issues are taken into account from the start on. In this project, this was realized by maintaining a close cooperation from the researchers with the regional care and housing organization of De Woonmensen, located in Apeldoorn, The Netherlands. This organization is currently reorganizing their way of working, shifting from rather large elderly homes with 100-200 elderly people living in one institution to the development of much more independent elderly homes where care is being supplied by the organization, but the elderly person remains independent. Next to these, a neighborhood center, a church, a physiotherapist, a children day-care center, and several other functionalities are part of the community. Next to this, several people with psychogeriatric illnesses like Alzheimer ${ }^{3}$ will be living in smaller communities. This shift of focus has created an interest from the organization to find out what opportunities certain technological innovations could bring to this new situation.

\footnotetext{
${ }^{3}$ Alzheimer is a specific psychogeriatric illness. In this paper, we will refer to "the elderly user with a tendency to wander off," when referring to the patients with Alzheimer or similar diseases.
}

From a system innovation perspective, the situation of focusing on the rather wide innovation area of De Woonmensen enabled the thinking about possible system changes in a niche environment. For this purpose, the research area should be large enough to see possibilities that span a wider scope than an innovation for one single user or organization. On the other hand, the area should be small enough to influence certain aspects that normally could not be changed on a nationwide scale. ${ }^{4}$

During the project, a wide feedback group has been created, involving representatives of all actors like the elderly users, the care personnel, the housing corporation, insurance companies, and commercial organizations. By means of workshops and in-depth interviews, the various perspectives of the actors involved have been taken into account. This involved, among others, commenting on several future scenarios that the researchers came up with.

Defining the focus points for the innovation process The research track being described in this paper focuses specifically on the area of communication of the inhabitants of the new neighborhood. As a starting point, the perspective from the elderly user was taken. The various relations and communication streams have been analyzed, focusing on the frequency of the contact in relation to the relevance of the relation. For

\footnotetext{
${ }^{4}$ For example in the healthcare situation, the way that certain solutions are (not) compensated by health insurers blocks many potential improvements, especially when they have a preventive instead of a curative nature. In a niche experiment, these solutions can be implemented on a smaller scale without worrying about the financial structure.
} 
Fig. 2 The V-cycle for system innovations, showing the various abstraction levels of the project, from (Joore 2006)

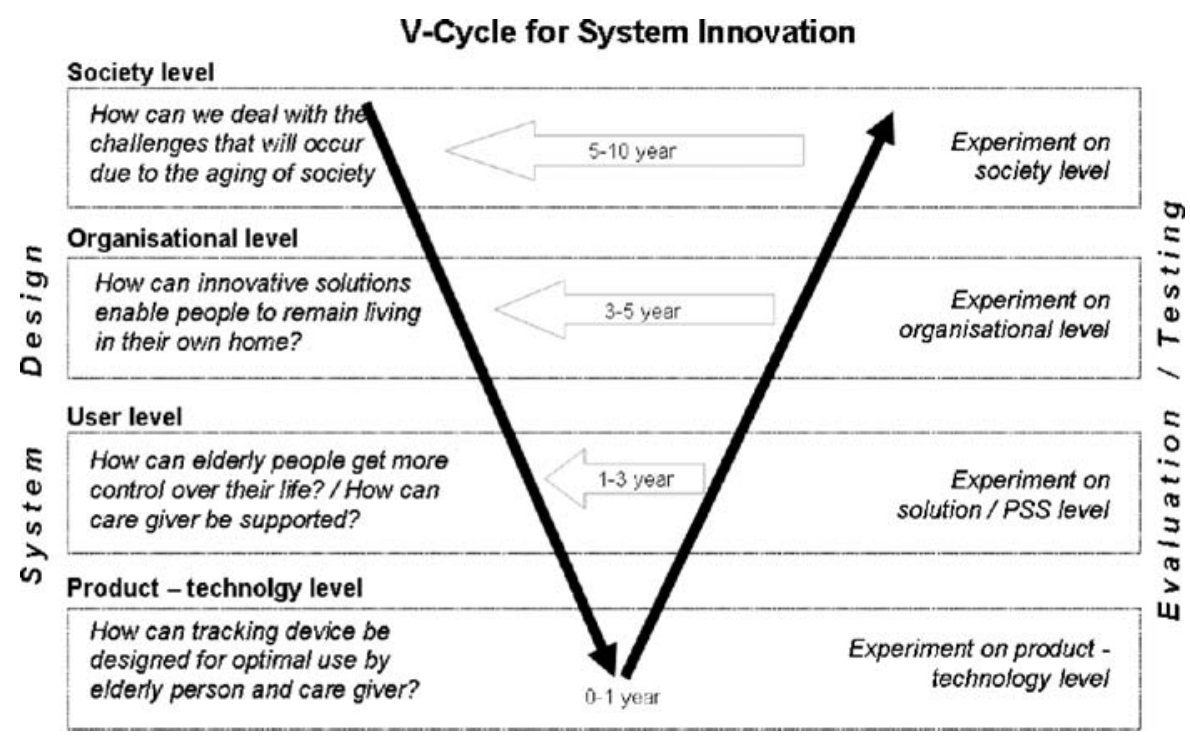

instance, contact with the police does not take place very often, but in case of an emergency, this contact is extremely important.

As a result of this analysis, three main need areas have been determined showing the most important issues in the decision-making process of elderly people and their relatives about their living condition. They determine to a large extent if a person remains living independently or has to move to an elderly home. The three areas are related to safety, social cohesion, and health. For each of those areas, four subgoals have been selected for the new system innovations to focus on:

Safety

- Knowing that there are people around that care about me and will help me when needed

- Being able to get help soon when an emergency happens, also when I am out of the home

- Knowing that me, my house, and my valuable things are safe against burglars, thieves, and criminals

- Being able to safely travel to various destinations, independently of others, at every time of the day

\section{Social Cohesion}

- Keeping regular and close social contacts with my family, friends, neighbors, also with relations that live far away
- Having a simple way to make social appointments

- Having a responsibility in the neighborhood, using my life experience and knowledge

- Understanding the people in the neighborhood, sharing similar values and norms

\section{Health}

- Having easy access to various care services like home care nurse, pedicure, hairdresser, food, and shopping goods

- Having good and easy access to medical services/ doctor, either face-to-face or on distance

- Having regular face-to-face personal contact with care personnel, with a high level of personal attention

- Knowing that my health is under control, but not having to know all the details every moment of the day

\section{Development of Future Visions}

The second step of the SSI method involves the creation of future visions looking several years ahead, showing a future that solves the described need areas, without worrying about the technological and economical limitations of this moment. The needs that have been selected in the previous step are the basis for the development of these "sustainable visions." 
No choice is made at this stage between the various needs, as the idea is to stimulate synergetic solutions that answer to several needs at the same time.

Setting the Innovation Guidelines: Three Kinds of Interaction Models As most needs defined in the previous step are related to interaction between users and other people, either from a social or from a professional perspective, several future visions have been developed using the level of interaction as the distinguishing factor. Three levels of interaction have been defined, varying in the level of personal involvement and technical involvement, being described as relation, networking, and autonomy. This differentiation is a variation on the Table Guidelines as described in (Manzini and Jegou 2003, pp 56-57).

Level A - Relation: This type of interaction concerns mainly face-to-face contact. One really knows and sees the people that one is communicating with and can actually touch them - going on a visit, having a chat at home, most things that we normally consider as personal contact. This type of interaction is the most personal, but also often the most time-consuming one.

Level B - Autonomy: In this level, the interaction is strongly supported by technical devices to assist in the communication. The technology takes such a strong role that almost no real personal contact needs to be established anymore. The advantage is that people can be more independent from others. The clear risk is the dependence on technology and the depersonalization of the interaction.

Level C - Networking: With this type of interaction, there is a level of personal contact, often combined with technological assistance to create more options. This form of interaction is more organized, communicating on a somewhat more formal level, for instance, meeting on set times and places. One does not have to see the other person, as the connection can take place with means of technical devices. However, face-to-face contact is an integral part of the communication options.

Based on these three interaction models (relation, autonomy, networking), focusing on the three defined need areas (safety, social cohesion, health), several future visions have been developed to create an integral vision of a sustainable future. By combining the three need areas, different solution elements can play a synergetic role in addressing all three need areas at the same time. The solution elements have been grouped in three "extreme" future visions, each called after the respective interaction model that was the basis of the vision.

Vision I: A Future Based on Relationships This first future vision is mainly relationship and service oriented, with a minimum of technology used. This vision can be compared to an old-fashioned village where everything is shared, like shared meals, shared knowledge passed on during coffee meetings, shared gardens, neighbors that help each other, shared system for tools and services. In this way, the social cohesion will grow as people are closely involved with the other inhabitants, and a safe and secure environment is encouraged because everybody helps and knows each other, and it seems there are no enemies or strangers around.

Examples of solution elements for relationship vision are:

- The neighborhood has dedicated people watching around to keep the common safety. Everyone has a personal nurse that is responsible for health care issues. A local policeman is always present to guard the area and take care of all security issue.

- In the neighborhood, there are several "relation networks." When someone is skilled for a specific task, he or she can offer this knowledge or service in an exchange center. If someone needs something, it is possible to go to the 
exchange point and ask if somebody can help. For each problem that is solved by a person, he or she receives a certain amount of credit that can be used to achieve other services.

- It is stimulated that people live with their relatives, and relatives can stay in a "family hotel", that enables visiting family to stay for a longer time. There is a local newspaper/bulletin in which all the things that happen around home are written down. There is information about the neighborhood, there are articles that are meant to teach people about a certain subject, there is information about courses and activities. In short, everyone knows everything about everyone and is able to take care of and protect each other.

Vision II: A Future Based on Autonomy The future vision based on autonomy has a strong focus on technology. The main part of all functionality is provided with technological means. The human involvement in the solution is kept as low as technically feasible. Whenever possible, human actions are replaced by technology. Human contact is still possible, but is maintained mainly by means of virtual interaction. Personal contact is achieved through screens, computers, holograms, 3-D glasses, virtual networks, and virtual group activities.

Examples of solution elements for autonomy vision are:

- An automated delivery system takes all goods to your home without the need to go outside. Food, medicine and other shopping goods are equipped with a tag that makes it possible that every good consumed is automatically registered and ordered.

- Beside the goods, also the inhabitants are equipped with a tag that they have to wear at all times. The tag is used to store information about the person containing information about their health situation, hobbies, address, and medicines that they are taking. The tags can identify the person at all times.

- Inhabitants that need regular visits from a doctor are equipped with a bed with built-in health sensors, remote controlled by a doctor. Through this bed, they will receive a regular virtual consult supported by the various body sensors. No more need for doctor's visits.
- Intelligent support devices are present everywhere in the community. The support devices perform all the routine tasks like cleaning the house, turning off the lights, watching for burglars, etc. There is almost never the need for a real person to be involved, as the intelligent support devices can solve most issues themselves.

Vision III: A Future Based on Technology-Mediated Networking In the networking vision, the focus lies on the balance between human involvement and technology. Technological options are used, keeping in mind that the technology should be an extension of the capabilities of people and not replacing him. Technology is used, but always with the aim of improving human interaction between people. Routine activities can be taken away by technological means, but the technology should support interaction and never replace eye-to-eye human contact. Although the difference is often a subtle one, the goal should be to enable people instead of disabling them (Manzini 2002).

Examples of solution elements for networking vision resemble the ones in the relationship vision, but they are supported by means of technological devices:

- In the neighborhood, there is an electronic "neighbor network." Everybody can be a member of this network. If something happens to one of the members, the other members can help. With one push on the smart assistant button, someone can ask help from one of the others. The nearest neighbor is located and asked for help. In this way, care services do not have to interact when it is not necessary.

- There is a database available in which everyone has a personal file with information about his interests and hobbies of the habitants. This way, it is possible to find and meet persons that have the same interests and join them at a central meeting place.

- Every person is equipped with an alarm device that works in two ways: either of the owners presses the alarm when one is in need. Other people can also send a warning signal when they have a problem or find themselves in a problematic situation. The device links the wearers of the device to each other, limiting the pressure on formal emergency organizations. 
As part of the development of the future visions, several solution elements, being smaller parts of more integrated solutions, have been translated in possible implementation scenarios. These have been visualized by means of storyboards, showing how a certain solution would function from the perspective of a user in his or her surrounding. No specific attention is placed on the technological basis of the specific solutions in this phase, only the actual functionality of the solution is shown.

\section{Backcasting, Roadmapping, and System Design}

In the next phase, the translations have taken place to put the various visions into a time perspective, showing what solution can be realized at what time. Based on the future scenarios and more specific solution element description, a workshop was organized where a group of relevant stakeholders from different background commented on the solutions from their own specific perspective. This resulted in the analysis of the solutions with regard to technological, organizational, and user perspective. As a result of this session, the critical success and failure factors of the solution elements were made clear.

In this paper, the description will focus on one specific solution track, being the Guide Me solution. From a more broad vision perspective, a wide range of solutions are needed to enable the ideal future visions. However, from a company perspective, it is counterproductive if this broader vision forces a specific way of working. Here, the tension between the more top-down vision and the more bottom-up regular commercial approach of the companies and other organizations becomes visible. The challenge being to use the future visions as inspiration and guidance for innovation, but preventing it from becoming a restrictive and binding process. The various actors should be free to follow their own way of working while being inspired by the opportunities that the broader future visions show them. Next to this, the possible cooperation with strategic partners during a niche experiment should offer attractive benefits to the organizations involved, thus motivating them to play their unique role in the fulfillment of the bigger vision.

In the Guide Me case, the benefits of four relevant actors were relevant. First, from a government or policy point of view, the growing amount of Alzheimer patients is a growing area of attention. ${ }^{5}$ As the amount of people suffering from Alzheimer will rise considerably as a result of the aging of society, this will cause a growing burden on the nations care system. The Alzheimer foundation in The Netherlands even started a campaign warning that Alzheimer can be a national disaster soon (Alzheimer Nederland 2003). Second, from the perspective of the Woonmensen organization, they have to deal with a growing amount of people suffering from this disease. The current reality is that at the moment that people start to have "wandering behavior," they have to be moved to a closed institution. With closed doors, the problem of wandering is prevented. However, with the new vision of all people living independently for a much longer time, there is a growing need to enable people to prevent locked doors, enabling people to go out freely with limited security risks. Third, one of the SMEs involved in the evaluation was the company My-Bodyguard BV. This company specialized in tracking devices for the security market, and the technology used in their products very well fits the technology needed for the Guide Me concept. For My-Bodyguard BV, the possibility of expanding their market to the new domain of care-related services and being able to test this functionality with the prospective end users at De Woonmensen living area was a relevant driver for innovation. Last, the possible input of available knowledge and technology of its own organization was an important driver for the TNO organization to support the development of the Guide Me solution.

The process of combining the possible technological solutions with the drivers of the various relevant actors has proven to one of the most challenging elements of the SSI process. Thus, we expect this area to be a relevant area of future research, providing more hands-on tools to enable the translation of broader future visions into short-term commercial innovations.

\footnotetext{
${ }^{5}$ About 130,000 people in the Netherlands suffer from Alzheimer. They are the majority of 180,000 people suffering any form of dementia. At the middle of this century, the amount of people suffering from dementia is expected to rise to 410,000 , of which there will be about 300,000 Alzheimer patients. That is 1 of every 57 inhabitants of The Netherlands (Internationale Stichting Alzheimer Onderzoek).
} 


\section{The Guide Me Concept}

The Guide Me concept mainly consists of a localization device that helps the caregiver to know where the user is at all times. The user carries a small tracking device, able to communicate with a computer or personal digital assistant (PDA) of the caregiver. Whenever the caregiver wants to know where a certain user is, he can see the location on a map on the computer or PDA. This functionality enables the patient to go about his or her daily life, for example, to go for a stroll or visit a friend, without supervision of a physically present caregiver. From the perspective of the caregiver, either professional or partner, the device is a technological support to give more ease of mind. Now, the caregiver no longer has to be alert at all times, watching out that the patient does not wander off. This results in the prolonged independence of the elderly person, delaying the need to move the person to a closed off living surrounding.

To further analyze the implications of the Guide Me system for the various actors involved, the system mapping method was developed in the highly customized solutions research project (Manzini et al. 2004, p. 107; Jegou and Joore 2004), showing the various information and material streams of the system. In the scheme, the various actors that are involved in the solution are shown, and the communication and material processes that are involved are shown by means of graphical visualizations. At this level, the function of the various products and services becomes clear, and the discussion with the relevant actors can take place.

One of the things that is clear from the system maps is the fact that the extension of the Guide Me concept with an alarm functionality has rather big implications for the system surrounding the solution. In the first version, the caregiver can only ask for the location of the user, and all actions are taken by the caregiver. This means that there is no extra functionality for the user. The extended version has an extra alarm functionality added for the user. As this alarm functionality needs be functioning at all times, the need arises to involve a 24-h call center and emergency organizations to follow up any call for help. For the Guide Me functionality, the choice was made to only focus on the functionality of the localization functionality, leaving out the option of the extra alarm function (Fig. 3).

To find out the feasibility of the Guide Me concept, a desktop investigation regarding similar existing products and services was done, and the possible bottlenecks when implementing the new Guide $\mathrm{Me}$ system were analyzed. Although several comparable products are on the market, they all have their respective limitations. One of the issues that surfaced was that even when people own products like a wearable alarm device or localization device, they have a strong tendency not to use them at all or only during a very limited amount of time of the day. This reduces the effectiveness of the device in a big way. Three reasons that were indicated for this were size, interface, and appearance, as existing products are very large and not easy to carry, products that are smaller have interfaces that are very difficult to handle for elderly people, and existing products often have a stigmatizing appearance.

Based on the preliminary desktop research results, in the next phase, the end users were involved in the analysis of the concept.

\section{Results from the Experiments}

The experimental activities have been divided in two parts, first introducing the concept through experience prototyping, then trying out the system with real functioning prototype products.

The experience prototyping test was especially focused on the potential benefits of the system for the caregivers. For this, the Guide Me Home concept has been researched with representative users using the method of experience prototyping. This means that no real device is needed yet, but the functionality of the system is simulated by a computer and by researchers who "act out" the solution behind the screens. The outcomes of this research have been described in Loh et al. (2004). From this experience of prototyping, it was clear that the Guide Me concept actually did create more ease of mind for users and caregivers, and a further elaboration of the system could be viable.

In the prototype experiment, a slightly modified, existing localization system is given to several elderly users and their caregivers, either partners or care personnel, who are using the system for several weeks. During this time, the behavior and experiences of the users have been determined, and in-depth interviews are held to find out the experience with the prototype product. 


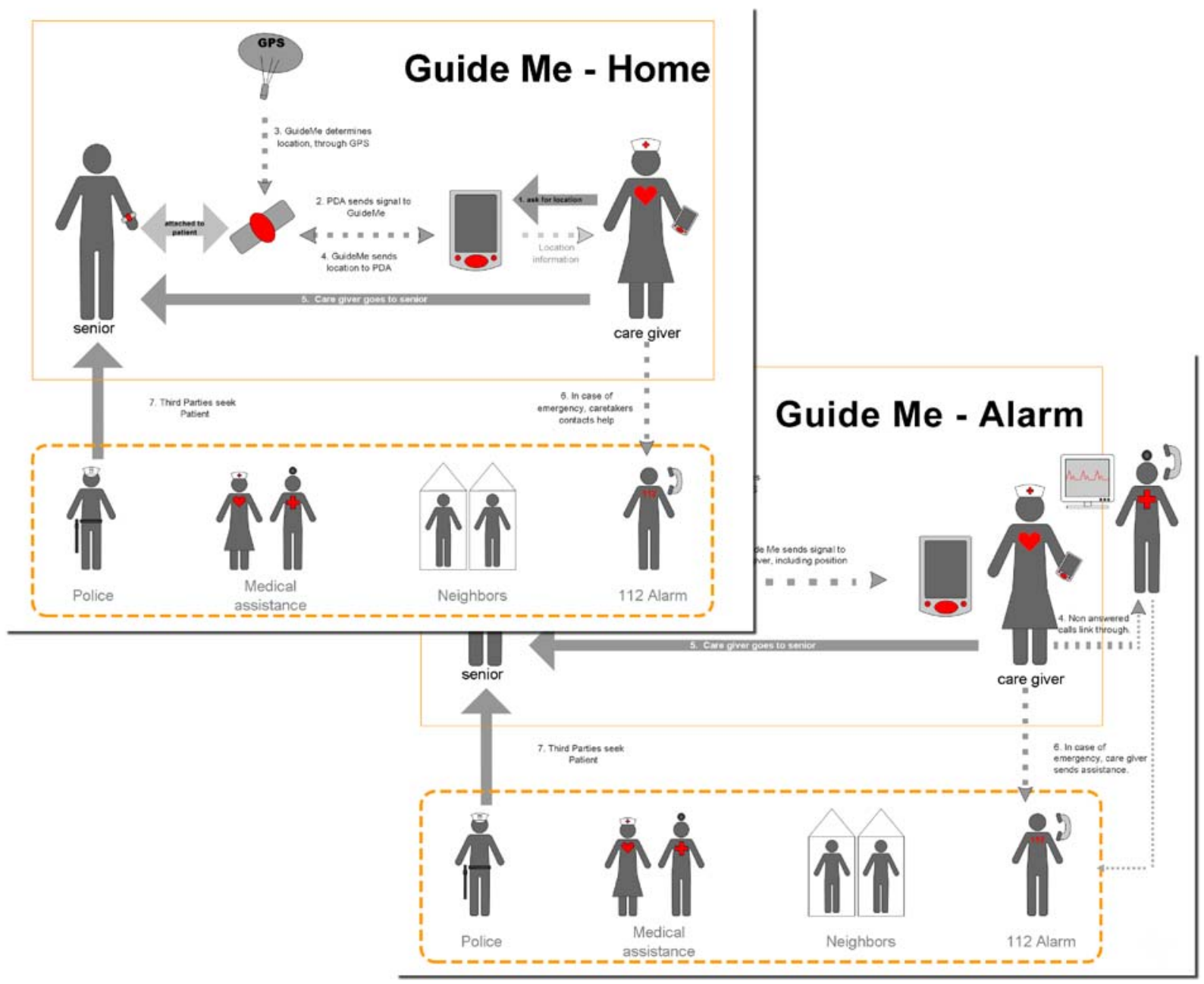

Fig. 3 Guide Me system maps

The results of the experiments can be divided in issues related to the care organization and more physical product-related issues.

With regard to the organizational issues, the following points were found:

- Financial support of the system by the government or insurance companies is lacking. The device can be considered as a preventive health measure, which at this moment is not covered by the main insurance and governmental organizations.

- Responsibility issues from a company perspective. The Guide Me device creates a feeling of safety with the users and their caregivers. However, how real is this feeling of safety? And who is responsible when an accident happens and the device does not function properly?

- Responsibility issues from the caregiver's perspective. When it is now possible to localize the position of a user at all times, who is actually responsible to perform this task? The following of the location of a patient could add another burden on the already stressed life of the caregiver, instead of relieving the task as intended.

With regard to the design of the physical product, a new user-related issue came to the surface in this phase, in addition to the already mentioned issues 
regarding size, interface, and appearance: With the increasing loss of memory, the functionality of a certain device is not always clear to the person suffering from Alzheimer. People who can sometimes not even recognize themselves in the mirror do not realize the functionality of a device that they need to carry with them. The other expected challenge is the needed discipline to charge the battery of the product everyday, again without direct functionality attached for the user.

Although the research has made it clear that organizational parameters play an important role in the successful realization of the Guide Me solution, the design perspective may still play a valuable role in answering some of the challenges regarding the use of the product. Here, the main area of attention focuses on finding new ways to stimulate users to take the device along, when there is no direct function attached to the product for them. One of the hypothesis now is that the customization or personalization of the device that is to be worn by the user could possibly benefit the acceptance by this user. When a personal touch would be added to the product, for instance, adding a personal picture to the device, this could improve the acceptance of this device by the user (Fig. 4).

In the next step of the research, concrete customization will take place using the technological basis of the existing product, developing several customized and personalized devices. From a process perspective, one could say that V-cycle process of Fig. 2 has been followed from the top macro level issue, related to the aging of society, all the way down to the microphysical product level, visualized by the left side of the V. In the evaluation of the solution, the questions need to be asked if this customization or personalization indeed leads to an increased user acceptance - if this increased acceptance then increased the actual use of the localization system? And if this then leads to increased control over ones own life, thus enabling the elderly person to remain living independently for a longer time? These questions describe the right side of the V-shaped process.

\section{Summary and Conclusions}

In the project described, a step-by-step approach has been followed to translate a specific challenge on macro level ("How can we deal with the challenges that occur due to the aging of society?") into a specific technological innovation challenge ("How can a tracking device be designed for optimal use by elderly person and care giver?"). The various SSI steps have proved to be valuable in translating this macro level need into a microlevel innovation issue.
Fig. 4 Functionality of the Guide Me system. Picture by Strategic Design Scenarios

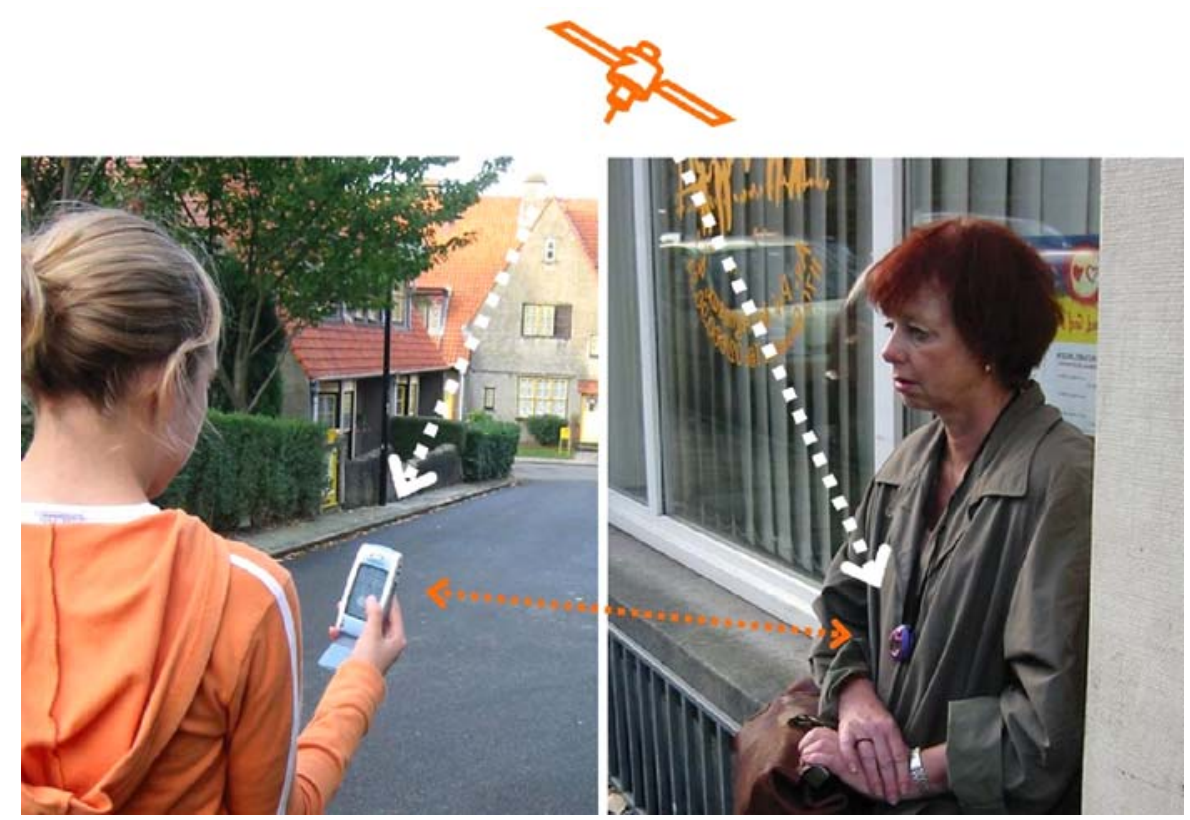


One of the main challenges of the described process lies in the selection of issues to focus on when descending in abstraction level. As the described future visions span a large range of solution elements, ranging from concrete products to services to government policy, the influence of each of these issues cannot easily be compared with each other. Different issues need to be realized by different actors, each with their own specific goals and drivers. The paper has described the translation of the more broad future vision into a specific innovation opportunity for a specific company and the issues that are relevant in this process.

An important potential benefit of the SSI approach is the way in which it can influence or inspire the various actors involved to all take a step in the preferred innovation direction. The inspirational strength of the future visions plays an important role in this process. For this purpose, the future vision should not only envision one or more possible futures, but should be much more the vision of a specific desirable future, introducing a more normative element to the described future visions. The process of deciding on the definition of this desirable future still needs further elaboration. A strong input of users, combined with the input of the other stakeholders, could be an important element of this process. However, to translate the objective input of users and stakeholders into a convincing and desirable perspective, the strength of the more subjective design vision is an important condition for success.

In the last phase of the research, the actual benefits of the selected microsolutions will be determined and the potential benefits of product personalization and customization to the functionality of the system. After finishing that phase, the SSI process has then been followed through from top macro level down to bottom microlevel, forming the left side of the Vcycle of system innovation. The evaluation process then needs to determine if the changes on microlevel, indeed, will result in the goals that have been set on macro level, forming the right side of the described $\mathrm{V}$-cycle for system innovations.

\section{References}

Alzheimer Nederland (2003), Jaarverslag, p. 5.

Centraal Bureau voor de Statistiek (2005), Bevolkingstrends, statistisch kwartaalblad over de demografie van Nederland, Jaargang 53, 2e kwartaal. Heerlen/Voorburg 2005.

Internationale Stichting Alzheimer Onderzoek (2006), http:// www.alzheimer.nl/ (Accessed October 2006)

Jegou, F. and Joore, P. (2004), Food delivery solutions, cases of solution oriented partnerships. Cranfield University. ISBN 1861-94-10-72

Joore, P. (2006), The V-Cycle for System Innovation, Translating a Broad Societal Need into Concrete Product Service Solutions, the Multifunctional Centre Apeldoorn Case. Proceedings of Sustainable Innovation 06, Global challenges issues and solutions, 23-24 October 2006, Chicago, USA, page 88-97.

Joore, P., Eikelenberg, N. and Schietecat, T. (2005), Improving independence of elderly people by introducing smart products. The Guide Me localization case. In Stephan Wensveen, Proceedings of DPPI 2005 - Designing Pleasurable Products and Interfaces (pp 431-450) Eindhoven, NL: Technische Universiteit Eindhoven.

Kemp, R. and Rotmans, J. (2001), The management of the coevolution of technical, environmental and social systems. Paper for International Conference Towards Environmental Innovation Systems, 27-29 September 2001, GarmischPartenkirchen.

Loh, J., Schietecat, T., Joore, P. et al. (2004), Technology applied to address difficulties of Alzheimer patients and their partners. Paper for conference Dutch Directions in HCI, Amsterdam, June.

Manzini, E. (2002), Context-based well-being and the concept of regenerative solution. A conceptual framework for scenario building and sustainable solutions development. Journal of Sustainable Product Design 2 (3-4):141-148.

Manzini, E., Jegou, F. (2003), Sustainable Everyday, Scenarios of Urban Life. Edizione Ambiente, ISBN 88-89014-01-6

Manzini, E., Collina, L., Evans, S. (2004), Solution Oriented Partnerships, How to Design Industrialised Sustainable Solutions. Cranfield University. ISBN 1861-94-10-64.

Weterings R. (2002), Nieuw initiatief duurzame systeem innovaties, bijgesteld ontwikkelingsplan 2003-2006. TNO, Apeldoorn/Delft, The Netherlands.

Peter Joore is senior project manager at TNO Science and Industry, leading multidisciplinary innovation projects focusing on radical innovations in the health domain. He is also working on his Ph.D. thesis at the Design for Sustainability group of the faculty of Industrial Design, Technical University Delft, studying success factors of multi-actor system innovations. 